\title{
La Investigación Científica en la Universidad.
}

\section{University research.}

\section{LLANOS CUENTAS, Alejandro}

Jefe de la Oficina de Investigación Científica

La Universidad, institución formadora de recursos humanos y generadora de conocimientos, cumple con su misión realizando actividades en las áreas de investigación, docencia y servicio. El cumplimiento de su rol en la sociedad requiere el desarrollo armónico de estas áreas.

La Universidad Peruana Cayetano Heredia (UPCH) es una institución privilegiada desde sus orígenes. Cuando fue creada en 1961 por 400 profesores, el común denominador fue la excelencia académica en docentes e investigadores provenientes de la Facultad de Medicina de la Universidad Nacional Mayor de San Marcos.

La UPCH durante sus primeros 30 años de existencia, mantiene un sólido prestigio nacional e internacional principalmente en las Américas el cual progresivamente se está incrementando en el Viejo Mundo. Sin embargo, es indudable que la crisis económica que afecta al Perú desde la década del 70, la cual se profundiza en los 80 , también afecta a la UPCH. Si bien se ha conseguido mantener un nivel en docencia e investigación por encima del promedio nacional, es indudable que algunos Departamentos Académicos de la Universidad han sido y están siendo afectados por la crisis.

Por otro lado el complejo panorama mundial en las últimas dos décadas se ha caracterizado por profundos cambios políticos y económicos. Como reconocen los economistas, el mundo está siendo afectado por problemas de inflación y/o recesión. La consecuencia directa de ello, es la restricción de fondos para investigación o actividades de ayuda a programas de desarrollo. Ante este panorama, una de las alternativas para elevar la riqueza mundial se afronta el reto de los cambios tecnológicos, generándose nuevos esquemas de reglas internacionales en diferentes campos, tanto económicos, académicos, de investigación, etc.

Durante la última década hemos observado tanto a nivel internacional, nacional y local, como los modelos basados en el apoyo estatal han fracasado. El Rector de la UPCH en más de una oportunidad ha señalado que el modelo de desarrollo de nuestra Universidad basado en el apoyo estatal se agotó, y que por lo tanto en los próximos años, el desarrollo de nuestra universidad debe estar basado en la capacidad que adquiera en generar sus propios recursos.

A pesar que la cantidad y calidad de las investigaciones generadas en la UPCH se ha mantenido por encima del promedio nacional, y en algunos campos se ha crecido internacionalmente, es cada vez mayor la distancia con el desarrollo de la investigación de 
los países desarrollados. La política de investigación que se ha seguido hasta la fecha en la UPCH depende del impulso de sus líderes. Esta política basada en "dejar hacer, dejar pasar" determinada una pérdida de oportunidades y recursos.

En un mundo cada vez más competitivo, en donde las fuentes de financiamiento se retraen y las opciones de financiamiento local son escasas, la alternativa para el fortalecimiento de la investigación en que nos permitan competir exitosamente por los fondos internaciones disponibles. El desarrollo sólido y profesional de la investigación en nuestra universidad está estrechamente relacionada a una mejor calidad de la enseñanza, al desarrollo del postgrado y también a una mejor calidad de servicio que podamos ofrecer a la comunidad nacional.

Desde el inicio de la presente gestión los miembros de la Oficina de Investigación Científica (OIC) están trabajando principalmente en la promoción de la investigación en la UPCH. Estas actividades tienden a solucionar las principales deficiencias en estímulo, facilidades y apoyo administrativo para la investigación, señaladas en el Segundo Seminario Taller de Planificación y Administración Estratégica, realizado en marzo de 1991.

En una primera fase, las actividades han estado dirigidas a estimular la investigación, en definir un reglamento de ética y en mejorar el apoyo, facilidades, y servicios que pueda ofrecer la OIC a la comunidad científica herediana. Ello está llevando a un progresivo y positivo acercamiento entre los investigadores y la OIC.

Para precisar mejor las actividades de la segunda fase ha elaborado y actualizado el inventario de investigación desde enero de 1989 a la fecha, para lo cual se ha utilizado los proyectos presentados a la OIC. El análisis de esta información ha sido expuesta en el Tercer Seminario Taller de Planificación y Administración Estratégica realizado en marzo de 1992 y nos ha permitido detectar las áreas donde tenemos que estimular la investigación, determinar los puntos en conflicto a ser intervenidos a través de propuestas específicas que están en elaboración.

Debido a que estas conclusiones están constituyendo la base para la preparación del plan de trabajo de la OIC en 1993, ponemos en conocimiento de la comunidad herediana las principales conclusiones del análisis del inventario de investigación. Estas son:

1. Los proyectos de investigación en la UPCH están en incremento, sin embargo es necesario adecuarse a las características y requerimientos que exige la investigación en la actualidad.

2. Los institutos son los lugares en donde se genera el mayor porcentaje de la investigación en la UPCH. La participación de los profesores en estas instituciones varía con los departamentos. Los profesores del Departamento de Medicina, son los que más han participado en los institutos, posiblemente por que sus investigaciones requieren de un apoyo multidisciplinario.

3. La investigación en la UPCH no es uniforme en sus departamentos. La mayoría tienen una baja productividad y baja participación en investigación. En algunos es 
prácticamente ausente. La investigación está centralizada en grupos, siendo los más exitosos los multidisciplinarios.

4. No se encontró diferencia en la participación en investigación entre los profesores a dedicación exclusiva y los de tiempo completo. Hubo clara diferencia con los profesores a tiempo parciales y horarios. La participación en investigación de estos últimos es poco significativa. De la misma forma, la participación en investigación entre los profesores principales y/o asociados fue similar, observándose diferencias con los auxiliares y contratados.

5. La investigación en la Universidad tiende cada vez a ser más colaborativa, existiendo un nivel de relaciones nacionales e internacionales óptimo, probablemente relacionado al prestigio de la Universidad.

6. Existen investigadores que están generando importantes proyectos que no son docentes de la UPCH. Este grupo podría ser fuente de profesores para la Universidad, principalmente en las áreas de Ciencias.

7. Los proyectos de ciencias con componentes de biología molecular, inmunología y los clínicos que incorporan aspectos básicos y epidemiológicos, tienden a incrementarse.

8. En el período de tres años que se ha extendido de 1989-1991, un 70\% de los proyectos presentados se ejecutan, sin embargo aproximadamente sólo un $10 \%$ del total son publicados.

Finalmente creo que uno de los aciertos de la actual administración de la UPCH, es el estar induciendo a la comunidad herediana a la reflexión y análisis de los múltiples problemas que nos afectan y el estimular para encontrar soluciones a ellos. Sin embargo, es conveniente integrar y articular estas alternativas de solución, de manera que permitan lograr un crecimiento armonioso, pragmático, y coherente con nuestra realidad. Esto nos permitirá estar preparados para afrontar con mejores posibilidades de éxito en un mundo cada vez más competitivo. 